\title{
Expression profile of C19MC microRNAs in placental tissue of patients with preterm prelabor rupture of membranes and spontaneous preterm birth
}

\author{
ILONA HROMADNIKOVA ${ }^{1}$, KATERINA KOTLABOVA ${ }^{1}$, KATARINA IVANKOVA ${ }^{2}$ and LADISLAV KROFTA ${ }^{2}$ \\ ${ }^{1}$ Department of Molecular Biology and Cell Pathology; ${ }^{2}$ Institute for The Care of Mother and Child, \\ Third Faculty of Medicine, Charles University, 10000 Prague 10, Czech Republic
}

Received October 6, 2016; Accepted July 3, 2017

DOI: $10.3892 / \mathrm{mmr} .2017 .7067$

\begin{abstract}
The aim of the study was to demonstrate that preterm birth (PTB) is associated with altered C19MC microRNA expression profile in placental tissues. Gene expression of 15 placental specific microRNAs (miR-512-5p, miR-515-5p, miR-516-5p, miR-517-5p, miR-518b, miR-518f-5p, miR-519a, miR-519d, miR-519e-5p, miR-520a-5p, miR-520h, miR-524-5p, miR-525-5p, miR-526a and miR-526b-5p) was compared between groups: 34 spontaneous PTB, 108 preterm prelabor rupture of membranes (PPROM) and 20 term in labor pregnancies. Correlation between variables including relative microRNA quantification in placental tissues and the gestational age at delivery, white blood cell (WBC) count at admission and serum levels of C-reactive protein at admission in patients with PPROM and PTB was determined. Expression profile of microRNAs was different between PPROM and term in labor pregnancies, PTB and term in labor pregnancies, and between gestational age-matched PPROM and PTB groups. When compared with term in labor pregnancies, while C19MC microRNAs showed a downregulation in PPROM pregnancies (miR-525-5p), in PTB pregnancies C19MC microRNAs were upregulated (miR-515-5p, miR-516-5p, miR-518b, miR-518f-5p, miR-519a, miR-519e-5p, miR-520a-5p, miR-520h, and miR-526b-5p) or showed a trend to upregulation (miR-519d and miR-526a). In comparison to PTB pregnancies, the PPROM group demonstrated a significant portion of downregulated C19MC microRNAs (miR-516-5p, miR-517-5p, miR-518b, miR-518f-5p, miR-519a, miR-519d, miR-519e-5p, miR-520a-5p, miR-520h, miR-525-5p, miR-526a and miR-526b-5p). In the group of PPROM pregnancies, a weak
\end{abstract}

Correspondence to: Professor Ilona Hromadnikova, Department of Molecular Biology and Cell Pathology, Third Faculty of Medicine, Charles University, Ruska 87, 10000 Prague 10, Czech Republic

E-mail: ilona.hromadnikova@lf3.cuni.cz

Key words: C19MC microRNAs, expression profile, preterm delivery, placental tissue, quantitative PCR negative correlation between the gestational age at delivery and microRNA gene expression in placental tissue for all examined C19MC microRNAs was observed. PTB pregnancies showed a positive correlation (miR-512-5p, miR-515-5p, miR-519e-5p) or a trend to positive correlation (miR-516-5p, miR-518b, miR-520h) between particular C19MC microRNAs and maternal WBC count at admission. Our study demonstrates that upregulation of $\mathrm{C} 19 \mathrm{MC}$ microRNAs is a characteristic phenomenon of PTB. PPROM pregnancies have a tendency to produce lower levels of miR-525-5p. All examined C19MC microRNAs displayed decreased expression with advancing gestational age in PPROM group.

\section{Introduction}

Preterm delivery, defined as the delivery prior 37 complete weeks of gestation, occurs in 5-13\% of all pregnancies (1-3). It is the most common cause of neonatal mortality and morbidity worldwide (2-5), accounts for approximately $70 \%$ of neonatal deaths $(6,7)$. Preterm delivery results from three clinical conditions occurring with nearly similar rates: i) Medically indicated or elective preterm delivery (30-35\%); ii) spontaneous preterm birth (PTB) with intact fetal membranes (40-45\%); and iii) premature rupture of fetal membranes (PROM; 25-30\%) $(2,8,9)$.

Preterm delivery results usually in critical care emergencies, and is associated not only with short-term consequences to the health of the child including cerebral palsy, respiratory distress syndrome, neonatal infection/sepsis and intraventricular hemorrhage, but also with long-term adverse sequel (i.e., neurodevelopmental impairment, sensory defects, learning difficulties and behavioural problems) (5,10-15).

Since preterm delivery rates increase over the last two decades in many developed countries (16), early identification (weeks if not months before the clinical event) of patients with an increased risk for PTB and PROM, as a prerequisite for the effective use of interventions (use of steroids, transfer to appropriate hospital facilities), becomes crucial in reducing adverse perinatal outcomes and the costs of neonatal care (5,17-19).

Although etiology of preterm delivery is multifactorial and the exact causes remain unknown in most cases, intrauterine infection with activation of the innate immune system 
and an exaggeration of inflammatory processes is found in $25-40 \%(9,20-23)$. Many other predisposing conditions have been proposed, including factors such as an incomplete cervix, uterine abnormalities, exposure to diethylstilbestrol (synthetic nonsteroidal estrogen; oral contraceptive) or environmental pollutants such as lead, pregnancy hypertension, intrauterine growth restriction, multiple pregnancy, maternal stress, heavy physical work, and smoking (24-27). Concerning intrauterine infection, development of histological chorioamnionitis is one of the main features and represents a pathological condition characterized by intraamniotic inflammation [AIA; inflammation of amniochorionic (fetal) membranes and placental chorion] in response to microbial invasion of the amniotic cavity (MIAC), which is predominated by Ureaplasma species, or to other pathological processes (28-30).

ROM is a natural physiological phenomenon that occurs before delivery. However, when the rupture of the amniotic membranes with release of the amniotic fluid occurs more than $1 \mathrm{~h}$ prior to the onset of labor, it is called PROM (31). PROM, that complicated $4.5-7.6 \%$ of deliveries $(32,33)$, may be subdivided into term PROM (TPROM; i.e., PROM after 37 weeks of gestation) and preterm PROM (PPROM; i.e., spontaneous rupture of fetal membranes prior 37 weeks of gestation) (31). Most women with PPROM deliver within $48 \mathrm{~h}$ after rupture. The incidence of PPROM is $2-3.5 \%$ (31). The management of patients with PROM offered two general, but still controversial, options: i) Prompt delivery for women in labor, when infection or irreversible fetal distress occurs; and ii) complex decision concerning prolonging of gestation, reducing of complications of prematurity, timing of labor and choosing the route of delivery for women not in labor, especially in premature gestational ages (34).

Many possible mechanisms underlying spontaneous PPROM, including intra-amniotic infection and other factors mentioned above, have been identified: Reduction of membrane collagen content stretched membranes, vasculopathy in placentation, decidual hemorrhage, placental abruption, uterine overdistension, nutritional deficiences, and genetic factors (i.e., race and familiar clustering) (33,35-37). All these factors may play primary or secondary roles in the pathogenesis of PPROM.

Based on the known risk factors and pathways, diagnosis of preterm delivery comprises clinical evaluation and biological tests, which are useful in the case of clinically asymptomatic patients. These tests include vaginal $\mathrm{pH}$ determination (nitrazine, bromthymol blue test) and the measurement of prolactin, $\alpha$-fetoprotein, inflammatory cytokine IL-6, diamine oxydase, insulin-like growth factor binding protein-1 (IGFBP-1), amniotic fluid intracellular adhesion molecule 1, human choriogonadotrophin levels, or fetal fibronectin in cervicovaginal fluid, respectively $(11,38-44)$.

Several biomarkers in first trimester maternal blood samples have been tested to see if they can predict preterm delivery. Among those rise in C-reactive protein (CRP) and decrease in mean platelet volume (MPV), pregnancy-associated plasma protein-A, selenium and lead levels in maternal serum during early gestation demonstrate some ability to distinguish women at risk of experiencing PTB or PPROM, but the insufficient test characteristics (specificity and sensitivity) of such methods limit any application in current clinical practice (45-50).
In the last decade, the importance of microRNAs (miRNA) in both, health and disease was revealed which provide a new opportunity for biomarker discovery in the field of preterm delivery. MicroRNAs belong to small (18-25 nucleotides) highly conserved single-stranded RNA molecules that play a critical role in posttranscriptional gene regulation by degrading or blocking translation of target messenger RNA. Although microRNA analyses indicate that a variety of disease-affected tissues display microRNA expression profiles that are significantly different from normal tissues, there are only several existing studies that have explored their possible involvement in regulating the molecular mechanisms that contribute to the pathophysiology of preterm delivery. First of all, Montenegro et al (51) screened 157 miRNAs using quantitative PCR in the chorioamniotic membranes derived from term and preterm patients and revealed a tendency toward decreased expression for 13 miRNAs with advancing gestational age. Evaluation of preterm membranes with and without chorioamnionitis identified increased expression of miR-223 and miR-338 in the presence of chorioamnionitis. Additional microRNA microarray analysis of 455 miRNAs in the chorioamniotic membranes revealed 39 differentially expressed microRNAs between term and preterm groups, of which 31 were downregulated at term. Subsequent quantitative PCR analysis confirmed decreased expression of miR-338, miR-449, miR-136, and miR-199a* in chorioamniotic membranes at term (52).

Another study (53) based on microarray profiling of 820 microRNAs in placentas identified 141 miRNAs (113 upregulated and 23 downregulated) differentially expressed in spontaneous preterm delivery ( $\leq 35$ weeks of gestation) compared to normal term pregnancies (elective caesarean section without labor). Validation analysis using quantitative PCR revealed that lower expression of miR-15b, miR-181, miR-210, miR-483-5p, and a trend toward higher expression of miR-496 were able to differentiate between preterm delivery, preeclampsia and term pregnancies.

Elovitz et al (54) analyzed miRNA expression levels in cervical cells obtained from the ectocervix by a cytobrush. Profiling of the 5,640 miRNAs in samples collected at 20 to 28 weeks of gestation showed 99 miRNAs expressed differentially in women who eventually had a preterm delivery compared with their term counterparts. Of these microRNAs, only three (miR-143, miR-145 and miR-199b-5p) were confirmed to be upregulated at 24 weeks to 28 weeks of gestation and just only one (miR-106b*) at 20 weeks to 24 weeks of gestation in women with a PTB.

Sanders et al (55), who studied microRNA expression levels in cervical cells obtained from swabs during pregnancy between 16 and 19 weeks of gestation, identified 6 miRNAs significantly associated with gestational age at the time of delivery. They found that the levels of certain microRNAs (miR-21, miR-30e, miR-142, miR-148b, miR-29b, and miR-223) in the human cervix during pregnancy were predictive of gestational age at delivery. Per each doubling in miR-21 or miR-30e, miR-142, miR-148b, miR-29b, and miR-223 expression, gestations were 0.9 or 1.0-1.6 days shorter, respectively.

Recent study by Elovitz et al (56) examined miRNA profile in maternal serum collected from women destined to have a preterm delivery compared with a term birth. Only 
4 out of 5,640 miRNAs (miR-200a*, miR-4695-5p, miR-665, and miR-887) were significantly different between cases and control subjects, however the fold difference in expression did not exceed 2, which limits their potential for clinical utilization.

Numerous studies have shown that alterations in miRNA expression in the placenta are associated with various pregnancy complications, such as preeclampsia and fetal growth restriction (57-62). The objective of this study was to investigate expression profile of C19MC miRNAs (miR-512-5p, miR-515-5p, miR-516b-5p, miR-517-5p, miR-518b, miR-518f-5p, miR-519a, miR-519d, miR-519e-5p, miR-520a-5p, miR-520h, miR-524-5p, miR-525-5p, miR-526a and miR-526b-5p) in placental tissues collected from women with PTB or PPROM. C19MC is the largest human miRNA gene cluster and consists of 46 genes encoding a total of 56 mature miRNAs (63). This cluster is only present in the primate and human genomes and expresses miRNAs almost exclusively in placenta (64), with expression detected in only a few other cell types such as embryonic stem cells and certain tumors (65-68). However, for testing we selected only those $15 \mathrm{C} 19 \mathrm{MC}$ microRNAs which, according to the miRNAMap database and the study presented by Liang et al (69), have been reported to be placenta specific (i.e., to be significantly expressed in the placenta while showing no or minimal expression in other tissues).

To our knowledge, no study on C19MC microRNA expression in PTB and PPROM has been carried out. Since placenta is a complex and vital organ that not only mediates the selective transfer of solutes and gasses between the mother and the fetus, but also produces hormones and other factors that support pregnancy, changes in miRNAs levels may lead to dysregulation of several proteins which can contribute to the mechanisms underlying pathogenesis of PTB or PPROM. We hypothesize that a distinct profile of C19MC miRNAs in placental tissues may differentiate between women with PTB, PPROM and term pregnancies in labor.

\section{Materials and methods}

Patients. The study was retrospective. Clinical samples were collected between 2013 and 2016 at the Institute for the Care of Mother and Child (Prague, Czech Republic). Samples processing and analyses were performed at the Department of Molecular Biology and Cell Pathology, Third Faculty of Medicine, Charles University (Prague, Czech Republic). The study protocol was approved by the appropriate Local Ethics Committees and all patients who participated in the study provided written informed consent.

Placental tissues were collected from pregnant women with singleton pregnancies only. The studied cohort consisted of 34 pregnancies with spontaneous PTB delivering within $25+1-36+5$ (median $34+5$ ) weeks of gestation, and 108 gestational age matched (range 24+0-36+6, median 34+2 weeks) pregnancies with PPROM. The control cohort consisted of 20 women at term in labor with normal course of gestation delivering healthy infants weighing $>2,500 \mathrm{~g}$ at term (after 37 completed weeks of gestation). Gestational age was assessed using ultrasonography.

PTB was defined as the occurrence of regular uterine contractions at a minimum frequency of two contractions per
$10 \mathrm{~min}$, along with cervical changes, leading to delivery before the 37th week of gestation was completed.

PPROM was defined as amniotic fluid leakage preceding the onset of labor by at least $2 \mathrm{~h}$. PPROM was diagnosed visually using a sterile speculum examination to confirm the pooling of amniotic fluid in the vagina and an alkaline $\mathrm{pH}$ of cervicovaginal discharge. When necessary, it was confirmed by a positive test for the presence of IGFBP-1 (ACTIM PROM test; Medix Biochemica, Kauniainen, Finland) in the vaginal fluid.

The exclusion criteria included women with gestational hypertension, preeclampsia, diabetes mellitus, significant vaginal bleeding, foetuses with the presence of congenital or chromosomal fetal abnormalities, signs of fetal growth restriction (an estimated weight below the 10th percentile for appropriate gestational age) and fetal hypoxia.

Women with PPROM and PTB at less than 34 weeks of gestation with negative markers of inflammation [maternal white blood cell (WBC) count and serum CRP levels] were treated with corticosteroids to accelerate lung maturation (one or maximally two doses of betamethasone administered intramuscularly $24 \mathrm{~h}$ apart). Tocolysis was used only in those patients before 34 weeks of gestation with no sign of fetal infection, fetal distress, maternal infection and negative perineal and perianal culture for GBS to allow the first course of antenatal corticosteroids to be completed and/or to transfer the patient to a tertiary care center. Prophylactic antibiotics were given to the majority of patients with preterm delivery to prevent signs of prepartum, intrapartum and postpartum infection.

In case of PPROM, induction of labor was initiated or an elective Cesarean section was performed within 24 to $72 \mathrm{~h}$ after the rupture of the membranes, depending on the gestational age of the pregnancy, the fetal status, the maternal serum levels of CRP and cervicovaginal Streptococcus $\beta$ colonization.

The clinical characteristics of normal and complicated pregnancies are presented in Table I.

Processing of samples. Samples of placenta were stored in RNAlater (Ambion, Austin, TX, USA) at $-80^{\circ} \mathrm{C}$ until further processing.

Total RNA was extracted from $25 \mathrm{mg}$ of placental tissue followed by an enrichment procedure for small RNAs (siRNAs, microRNAs), according to manufacturer's instructions using mirVana microRNA Isolation kit (Ambion). To minimize DNA contamination, we treated the eluted RNA with $5 \mu 1$ of DNase I (Fermentas international, Inc., Burlington, ON, Canada) for $30 \mathrm{~min}$ at $37^{\circ} \mathrm{C}$. Using this approach, a RNA fraction highly enriched in RNA species $<200$ nt was obtained, whose concentration and quality was assessed using a NanoDrop ND-1,000 spectrophotometer (NanoDrop Technologies, Wilmington, DE, USA). The A (260/280) absorbance ratio of isolated RNA was 1.8-2.0, demonstrating that the RNA fraction was pure and could be used for analysis. Additionally, the A (260/230) ratio was greater than 1.6, demonstrating negligible contamination by polysaccharides.

Reverse transcriptase reaction using a stem-loop primer. Each of the 15 microRNAs (miR-512-5p, miR-515-5p, miR-516-5p, 


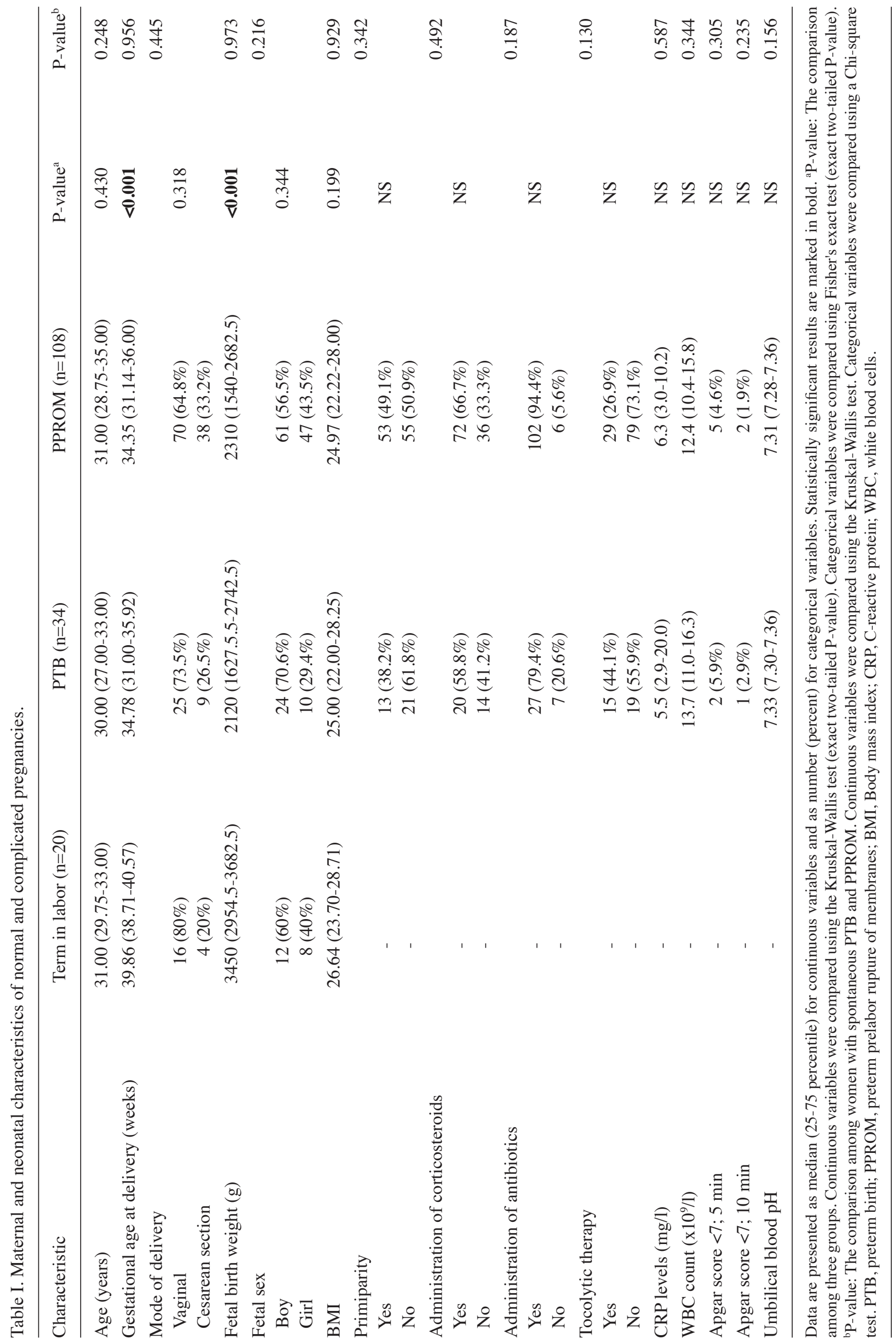


miR-517-5p, miR-518b, miR-518f-5p, miR-519a, miR-519d, miR-519e-5p, miR-520a-5p, miR-520h, miR-524-5p, miR-525-5p, miR-526a and miR-526b-5p) was reverse transcribed into complementary DNA (cDNA) using a TaqMan MicroRNA Assay, containing microRNA-specific stem-loop RT primers, and a TaqMan MicroRNA Reverse Transcription kit (Applied Biosystems, Branchburg, NJ, USA) in a total reaction volume of $32 \mu \mathrm{l}$, according to manufacturer's instructions. Reverse transcriptase reactions were performed using a 7,500 Real-Time PCR system (Applied Biosystems) with the following thermal cycling parameters: $30 \mathrm{~min}$ at $16^{\circ} \mathrm{C}$; $30 \mathrm{~min}$ at $42^{\circ} \mathrm{C} ; 5 \mathrm{~min}$ at $85^{\circ} \mathrm{C}$; and then held at $4^{\circ} \mathrm{C}$. Finally, 20 ng of the RNA template was used for each RT reaction. The characteristics of studied C19MC microRNAs are outlined in Table II.

Relative quantification of microRNAs by quantitative PCR. $15 \mu \mathrm{l}$ of cDNA, corresponding to each selected microRNA, were mixed with specific primers and the TaqMan MGB probe (TaqMan MicroRNA Assay; Applied Biosystems,), and the ingredients of the TaqMan Universal PCR Master Mix (Applied Biosystems) in a total reaction volume of $35 \mu \mathrm{l}$. The analysis was performed using a 7,500 Real-Time PCR System. TaqMan PCR conditions were set as described in the TaqMan guidelines using 50 cycles of $95^{\circ} \mathrm{C}$ for $15 \mathrm{sec}$ and $60^{\circ} \mathrm{C}$ for 1 min with 2 -min preincubation at $50^{\circ} \mathrm{C}$ required for optimal AmpErase UNG activity and $10-\mathrm{min}$ preincubation at $95^{\circ} \mathrm{C}$ required for activation of AmpliTaq Gold DNA polymerase. All PCRs were performed in duplicate. Multiple negative controls such as NTC (water instead of cDNA sample), NAC (non-transcribed RNA samples), and genomic DNA (isolated from equal biological samples) did not generate any signals during PCR reactions. Each sample was considered positive if the amplification signal occurred before the 40th quantification cycle $\left(\mathrm{C}_{\mathrm{q}}<40\right)$.

The expression of particular microRNA was determined using the comparative $\mathrm{C}_{\mathrm{q}}$ method (70) relative to normalization factor (geometric mean of three selected endogenous controls) (71). RNA isolated from a randomly selected placenta derived from a normal gestation was chosen as a reference for each comparison. RNA that was highly enriched with small RNA, isolated from the fetal part of the placenta (the part of the placenta derived from the chorionic sac that encloses the embryo, consisting of the chorionic plate and villi), was used as a reference sample for relative quantification throughout the study.

All 15 selected microRNAs were reliably detectable in the fetal part of the placenta, when a fixed concentration of RNA (5 $\mathrm{ng} / \mu \mathrm{l}$ ) was used in the analysis; however their expression differed significantly with respect to various $\mathrm{C}_{\mathrm{q}}$ values, ranging from 17.4 to 35.2 (72).

The difference $(\Delta \mathrm{Cq})$ between the $\mathrm{C}_{\mathrm{q}}$ values of particular microRNA and the internal control (geometric mean of three selected endogenous controls: RNU6B, RNU38B and synthetic $C$. elegans microRNA cell-miR-39 was calculated for each sample). Synthetic $C$. elegans microRNA was used as an internal control for variations during the preparation of RNA, cDNA synthesis, and quantitative PCR. The comparative $\Delta \Delta \mathrm{Cq}$ calculation involved finding the difference between each sample's $\Delta \mathrm{Cq}$ and the reference's $\Delta \mathrm{Cq}$. Finally, $\Delta \Delta \mathrm{Cq}$

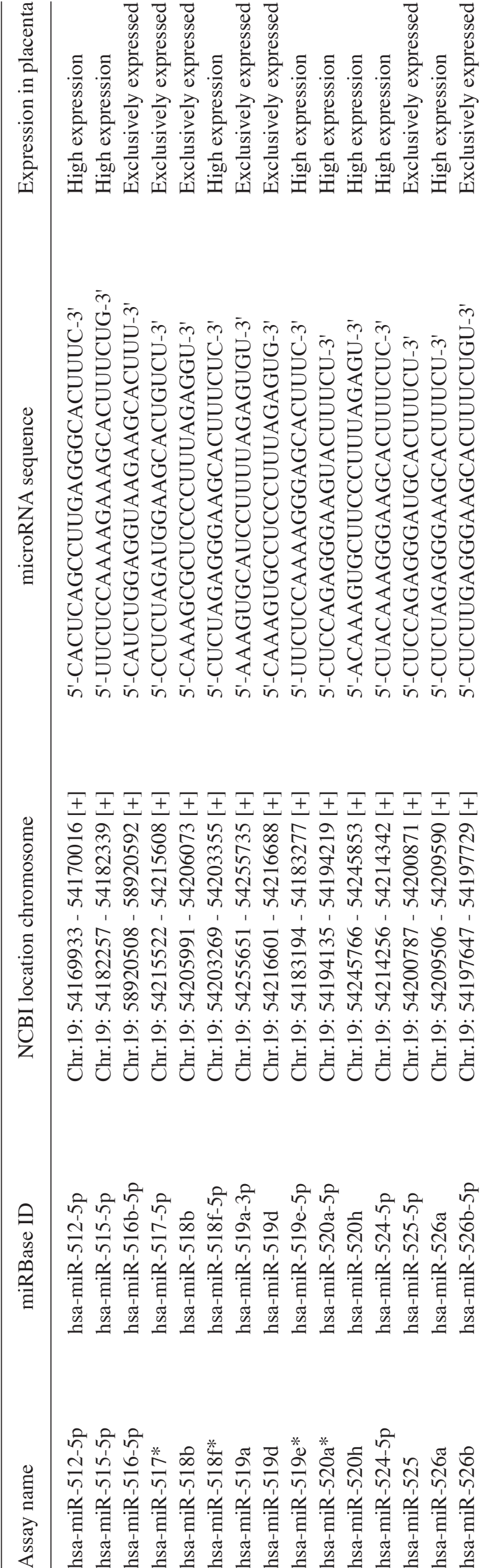


values were transformed to absolute values using the formula $2^{-\Delta \Delta \mathrm{Cq}}$. This distinctive approach allows long-term, large-scale analysis composed of multiple analyses performed at different periods.

Statistical analysis. Data normality was assessed using the Shapiro-Wilk test, which showed that our data did not follow a normal distribution. Therefore, microRNA levels were compared between groups using non-parametric tests (the Mann-Whitney $U$ test for the comparison between two groups and the Kruskal-Wallis test for the comparison among multiple groups). $\mathrm{P}<0.05$ was considered to indicate a statistically significant difference.

Data analysis was performed and box plots were generated using Statistica software (version 9.0; StatSoft, Inc., Tulsa, OK, USA). Each box encompasses the median (dark horizontal line) of log-normalized gene expression values for microRNAs of interest in cohorts; the upper and lower limits of the boxes represent the 75 and 25 th percentiles, respectively. The upper and lower whiskers represent the maximum and minimum values that are no more than 1.5 times the span of the interquartile range (range of the values between the 25th and the 75 th percentiles). Outliers are indicated by circles and extremes by asterisks.

Correlation between variables including relative microRNA quantification in placental tissues and the gestational age at delivery, maternal WBC count at admission (x10 $/ 1)$, maternal serum levels of CRP at admission $(\mathrm{mg} / \mathrm{l})$ in patients with PPROM and PTB was calculated using the Spearman's rank correlation coefficient (rho). If the correlation coefficient value is -1 or 1 , there is a perfect negative or positive correlation. If it ranges within $<-1 ; 0.5>$ or $\langle 0.5 ; 1>$, there is a strong negative or positive correlation. If it varies from -0.5 to 0 and from 0 to 0.5 , there is a weak negative or positive correlation. The significance level was established at a $\mathrm{P}$-value of $\mathrm{P}<0.05$.

\section{Results}

Initially, gene expression of C19MC microRNAs was compared between the groups of women at term in labor, spontaneous PTB and PPROM. Consecutively, an effect of gestational age on C19MC microRNA gene expression was evaluated in the group of PPROM and PTB patients.

Moreover, the association between C19MC microRNA gene expression in placental tissue and maternal WBC count and maternal serum CRP levels in patients with PPROM and PTB was determined.

Downregulation of C19MC microRNAs in PPROM pregnancies and upregulation of C19MC microRNAs in PTB pregnancies. Overall, the expression of C19MC microRNAs in placental tissue samples differed significantly or was on the border of statistical significance between the control group (term in labor pregnancies) and pregnancies affected with PPROM or PTB. While decreased expression of 1/15 C19MC microRNAs was observed in women with PPROM (miR-525-5p, $\mathrm{P}=0.025$ ), the upregulation of $9 / 15 \mathrm{C} 19 \mathrm{MC}$ microRNAs was found in PTB pregnancies (miR-515-5p, $\mathrm{P}=0.040$; miR-516b-5p, $\mathrm{P}=0.032$; miR-518b, $\mathrm{P}=0.039$; miR-518f-5p, $\mathrm{P}=0.036$; miR-519a, $\mathrm{P}=0.032$; miR-519e-5p,
$\mathrm{P}=0.006$; miR-520a-5p, $\mathrm{P}=0.014 ; \mathrm{miR}-520 \mathrm{~h}, \mathrm{P}=0.039$; and miR-526b-5p, $\mathrm{P}=0.022$ ). The difference on the border of statistical significance was identified between the groups of PTB patients and term in labor pregnancies for miR-519d $(\mathrm{P}=0.067)$ and miR-526a ( $\mathrm{P}=0.067)$ (Fig. 1, Table III).

Differentiation between gestational age-matched pregnancies with PTB and PPROM based on placental expression profile of C19MC microRNAs. Overall, the expression of miR-516b-5p $(\mathrm{P}=0.009)$, miR-517-5p $(\mathrm{P}=0.021)$, miR-518b $(\mathrm{P}=0.009$, miR-518f-5p $(\mathrm{P}=0.033), \mathrm{miR}-519 \mathrm{a} \quad(\mathrm{P}=0.022)$, miR-519d $(\mathrm{P}=0.003)$, miR-519e-5p $(\mathrm{P}=0.016)$, miR-520a-5p $(\mathrm{P}=0.018)$, miR-520h $(\mathrm{P}=0.005)$, miR-525-5p $(\mathrm{P}=0.015)$, miR-526a $(\mathrm{P}=0.006)$ and miR-526b-5p $(\mathrm{P}=0.007)$ differed significantly between the PTB group and pregnancies affected with PPROM. Lower expression rates were detected in patients with PPROM. A trend towards statistical significance for downregulation of miR-524-5p $(\mathrm{P}=0.064)$ was observed for PPROM pregnancies (Fig. 1, Table III).

The effect of the gestational age on C19MC microRNA expression in placental tissue within the groups of PPROM and PTB pregnancies. A weak negative correlation between the gestational age at delivery and microRNA gene expression in placental tissue within the group of PPROM patients was observed (miR-512-5p, $\rho=-0.344, P=0.002$; miR-515-5p, $\rho=-0.342, P=0.002$; miR-516b-5p, $\rho=-0.293, P=0.010$; miR-517-5p, $\rho=-0.258, P=0.023$; miR-518b, $\rho=-0.375, P<0.001$; miR-518f-5p, $\rho=-0.316, P=0.005 ; \operatorname{miR}-519 a, \rho=-0.293$, $\mathrm{P}=0.010 ; \mathrm{miR}-519 \mathrm{~d}, \rho=-0.333, \mathrm{P}=0.003$; $\mathrm{miR}-519 \mathrm{e}-5 \mathrm{p}$, $\rho=-0.278, P=0.014 ;$ miR-520a-5p, $\rho=-0.257, P=0.024$; miR-520h, $\rho=-0.334, P=0.003$; miR-524-5p, $\rho=-0.351$, $\mathrm{P}=0.001 ; \operatorname{miR}-525-5 \mathrm{p}, \rho=-0.284, \mathrm{P}=0.012$; $\mathrm{miR}-526 \mathrm{a}$, $\rho=-0.308, P=0.006$; and miR-526b-5p, $\rho=-0.453, P<0.001$ ), which means that the expression of all 15 examined C19MC microRNAs decreased with advancing gestational age at delivery (Fig. 2). On the other hand, no association between microRNA gene expression in placental tissue and the gestational age at delivery was found in the group of PTB patients.

The association between C19MC microRNA gene expression in placental tissue and maternal serum CRP levels within the groups of PPROM and PTB pregnancies. No association between maternal serum CRP levels at admission and C19MC microRNA gene expression levels in placental tissues was found in the group of PPROM pregnancies (miR-512-5p: $\rho=-0.117$, $\mathrm{P}=0.333$; miR-515-5p, $\rho=-0.131, \mathrm{P}=0.276$; $\mathrm{miR}-516 \mathrm{~b}-5 \mathrm{p}$, $\rho=-0.105, P=0.384 ;$ miR-517-5p, $\rho=-0.167, P=0.164$; miR-518b, $\rho=-0.112, P=0.354 ;$ miR-518f $-5 p, \rho=-0.154, P=0.202$; miR-519a, $\rho=-0.149, P=0.215$; miR-519d, $\rho=-0.160, P=0.183$; miR-519e-5p, $\rho=-0.167, \mathrm{P}=0.166 ; \mathrm{miR}-520 \mathrm{a}-5 \mathrm{p}, \rho=-0.142, \mathrm{P}=0.238$; miR-520h, $\rho=-0.134, P=0.268$; miR-524-5p, $\rho=-0.188, P=0.117$; miR-525-5p, $\rho=-0.145, P=0.229$; miR-526a, $\rho=-0.143, P=0.235$; and miR-526b-5p, $\rho=-0.027, P=0.823$ ) and $\mathrm{PTB}$ pregnancies (miR-512-5p, $\rho=0.144, \mathrm{P}=0.594$; $\mathrm{miR}-515-5 \mathrm{p}, \rho=0.114, \mathrm{P}=0.672$; miR-516b-5p, $\rho=-0.058, P=0.828$; $\operatorname{miR}-517-5 p, \rho=0.036$, $\mathrm{P}=0.892$; miR-518b, $\rho=-0.151, \mathrm{P}=0.575$; miR-518f-5p, $\rho=-0.091$, $\mathrm{P}=0.736$; miR-519a: $\rho=-0.139, \mathrm{P}=0.605$; miR-519d, $\rho=0.035$, $\mathrm{P}=0.896$; miR-519e-5p, $\rho=-0.061, \mathrm{P}=0.820$; miR-520a-5p, $\rho=-0.005, P=0.982$; miR-520h, $\rho=0.064, P=0.811$; miR-524-5p, 

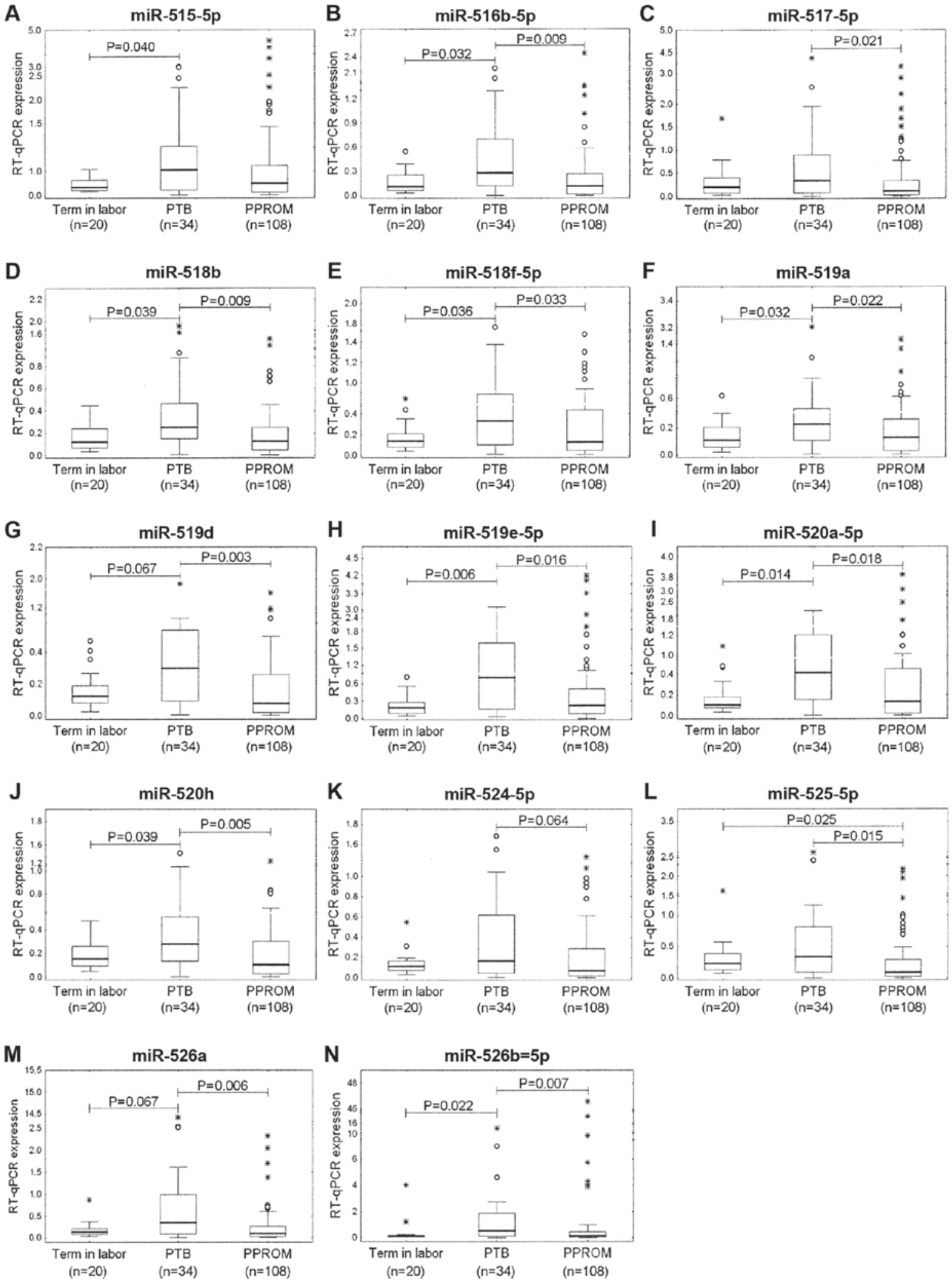

Figure 1. Downregulation of C19MC microRNAs in PPROM pregnancies and upregulation of C19MC microRNAs in PTB pregnancies. Differentiation between gestational age matched PTB and PPROM pregnancies. Gene expression of C19MC microRNAs was compared between the groups of women at term in labor (20), spontaneous preterm birth (34 PTB) and preterm prelabor rupture of membranes (108 PPROM) using the Kruskal Wallis test for the comparison among multiple groups. The significance level was established at $\mathrm{P}<0.05$. While decreased expression of (L) miR-525-5p was observed in women with PPROM, the upregulation of (A) miR-515-5p, (B) miR-516b-5p, (D) miR-518b, (E) miR-518f-5p, (F) miR-519a, (H) miR-519e-5p, (I) miR-520a-5p, (J) miR-520h and (N) miR-526b-5p was found in PTB pregnancies. The expression of (B) miR-516b-5p, (C) miR-517-5p, (D) miR-518b, (E) miR-518f-5p, (F) miR-519a, (G) miR-519d, (H) miR-519e-5p, (I) miR-520a-5p, (J) miR-520h, (L) miR-525-5p, (M) miR-526a and (N) miR-526b-5p differed significantly between the PTB group and pregnancies affected with PPROM. Data analysis was performed and box plots were generated using Statistica software (version 9.0; StatSoft, Inc., Tulsa, OK, USA). Each box encompasses the median (dark horizontal line) of log normalized gene expression values for microRNAs of interest in cohorts; the upper and lower limits of the boxes represent the 75th and 25th percentiles, respectively. The upper and lower whiskers represent the maximum and minimum values that are no more than 1.5 times the span of the interquartile range (range of the values between the 25 and the 75 th percentiles). Outliers are indicated by circles and extremes by asterisks. 


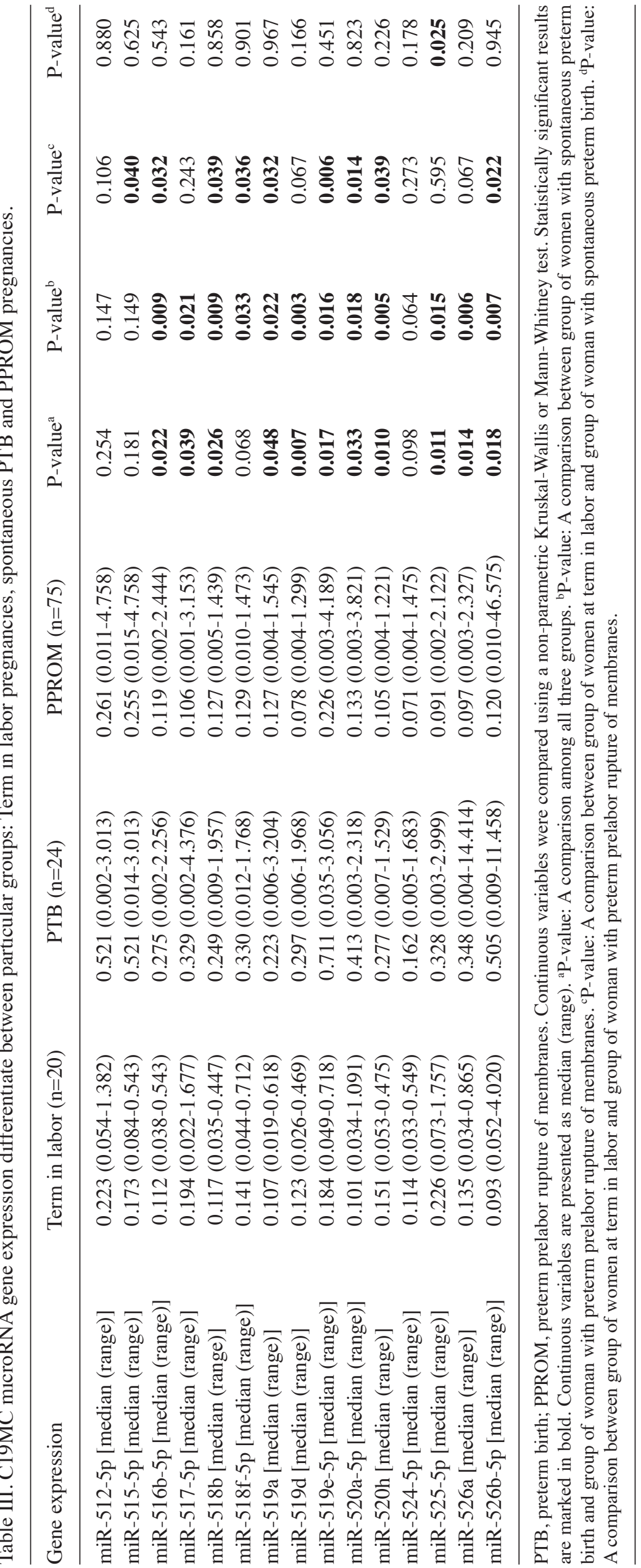


A

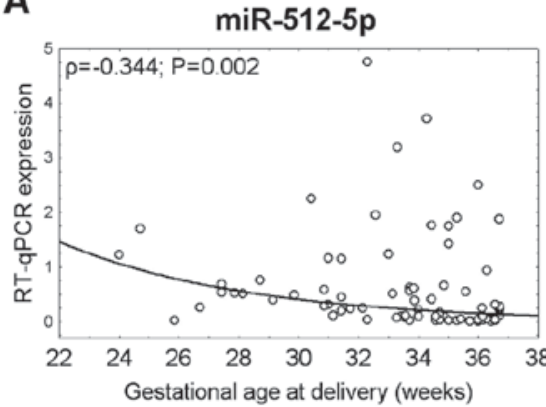

D

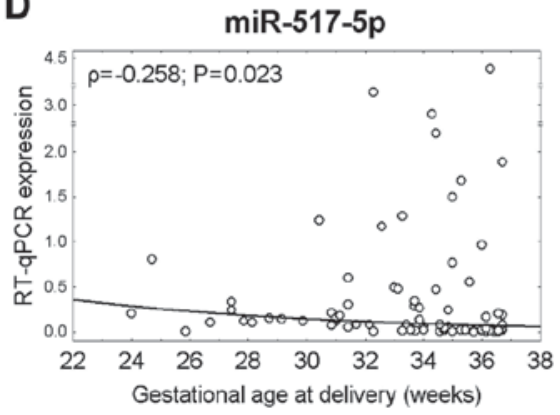

G

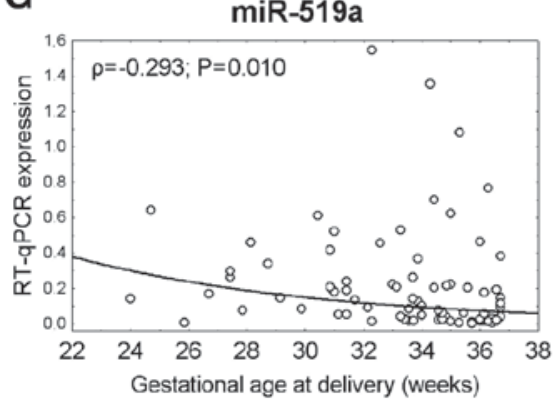

J

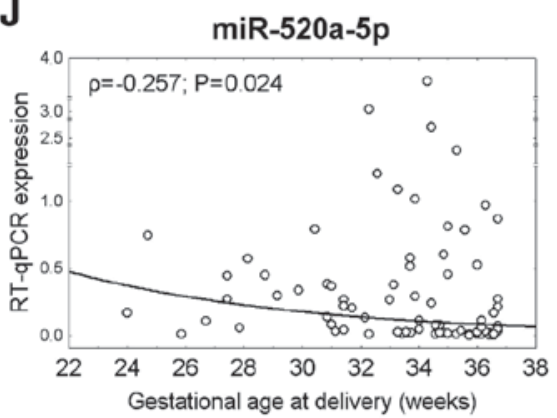

M

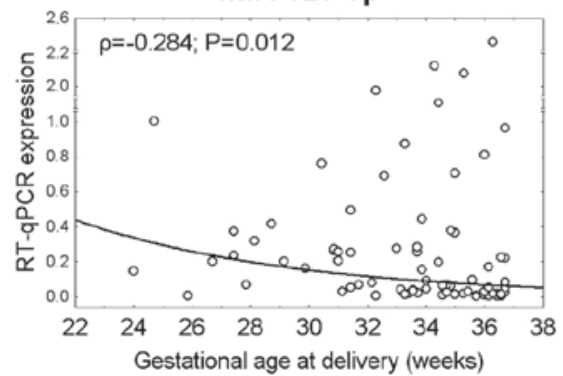

B

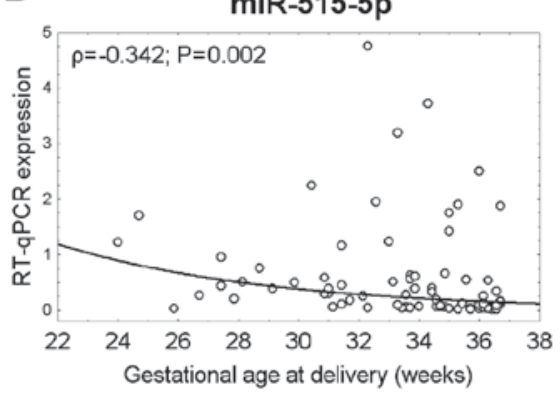

E

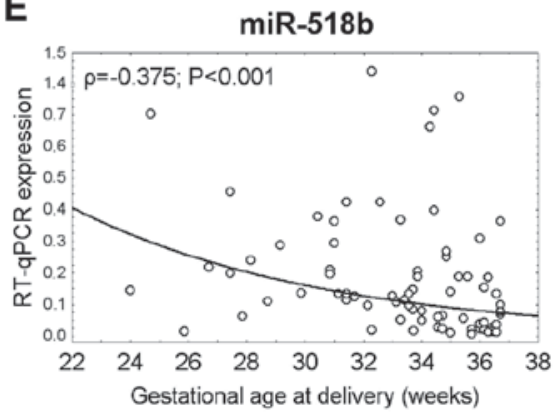

H

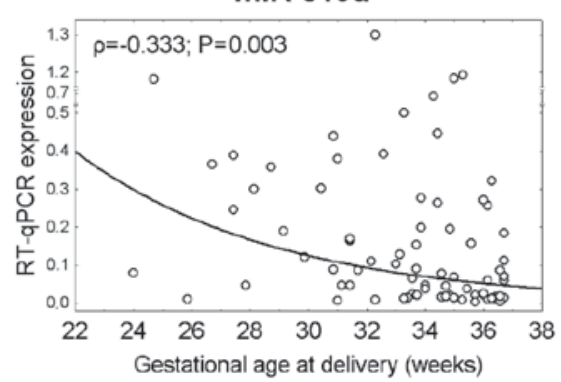

K

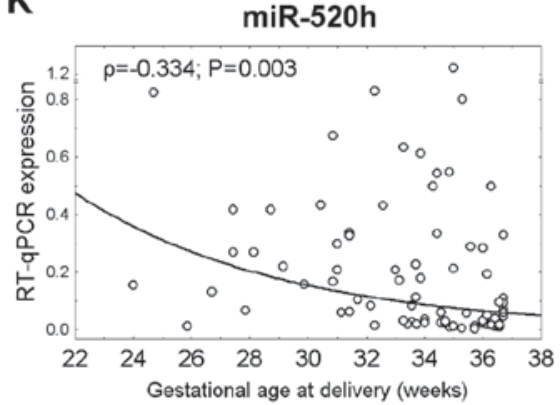

N

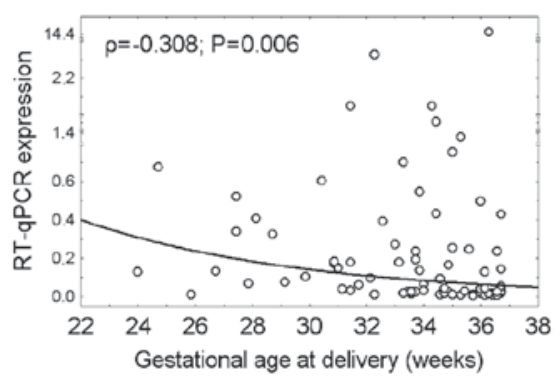

C

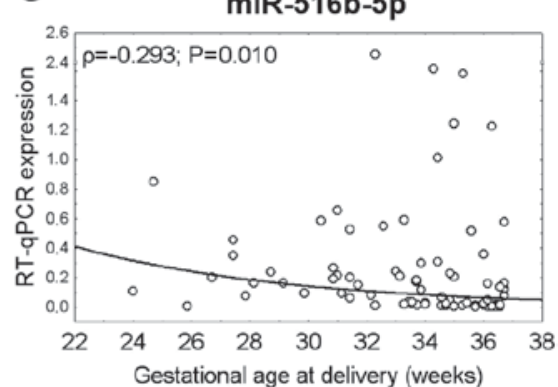

F

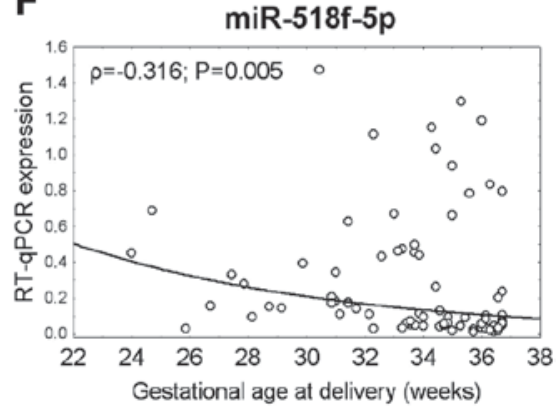

I

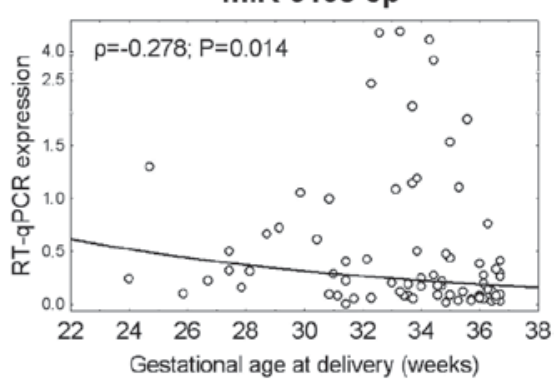

L $\quad$ miR-524-5p

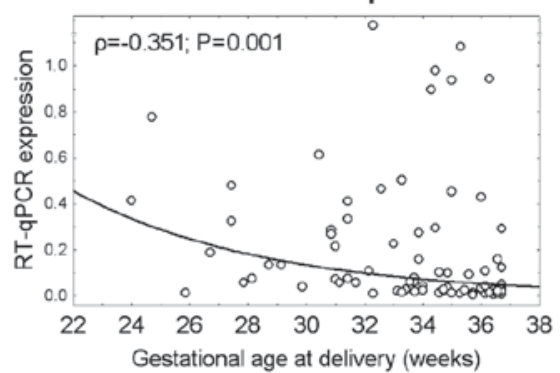

0

miR-526b-5p

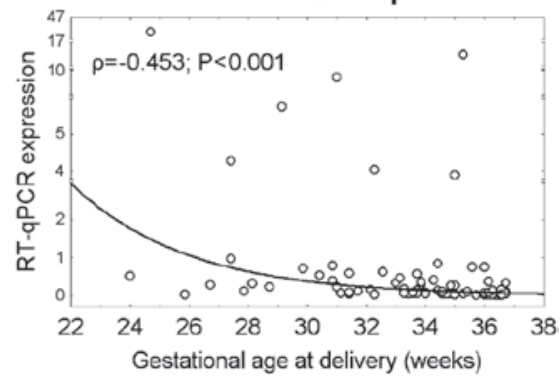

Figure 2. Decline of C19MC microRNA expression in placental tissues with advancing gestational age in the group of preterm prelabor rupture of membranes (PPROM) pregnancies. Correlation between variables including relative microRNA quantification in placental tissues and the gestational age at delivery in patients with PPROM was calculated using the Spearman's rank correlation coefficient (rho). If the correlation coefficient value varies from 0.5 to 0 , there is a weak negative correlation. The significance level was established at $\mathrm{P}<0.05$. A weak negative correlation between the gestational age at delivery and gene expression of (A) miR-512-5p, (B) miR-515-5p, (C) miR-516b-5p, (D) miR-517-5p, (E) miR-518b, (F) miR-518f-5p, (G) miR-519a, (H) miR-519d, (I) miR-519e-5p, (J) miR-520a-5p, (K) miR-520h, (L) miR-524-5p, (M) miR-525-5p, (N) miR-526a and (O) miR-526b-5p in placental tissue within the group of PPROM patients was observed. 
A

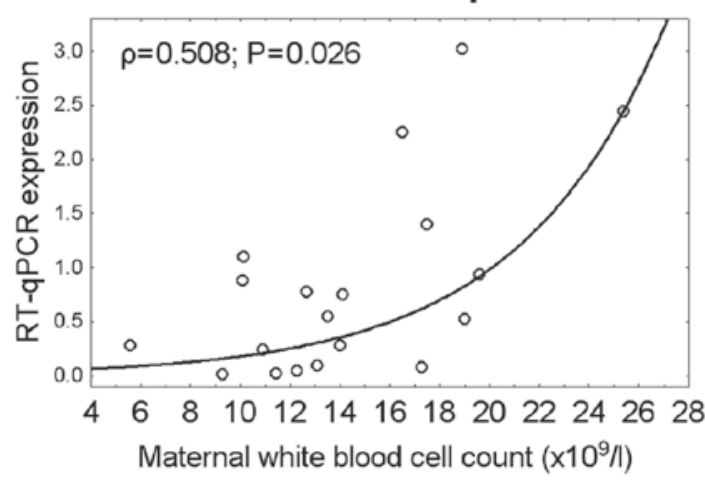

C

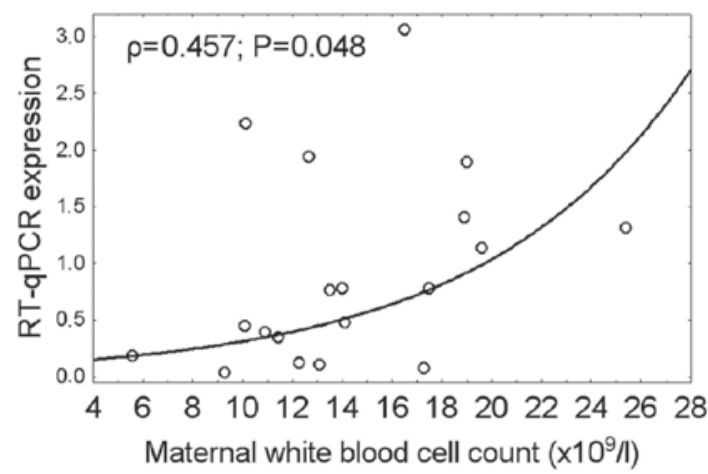

E

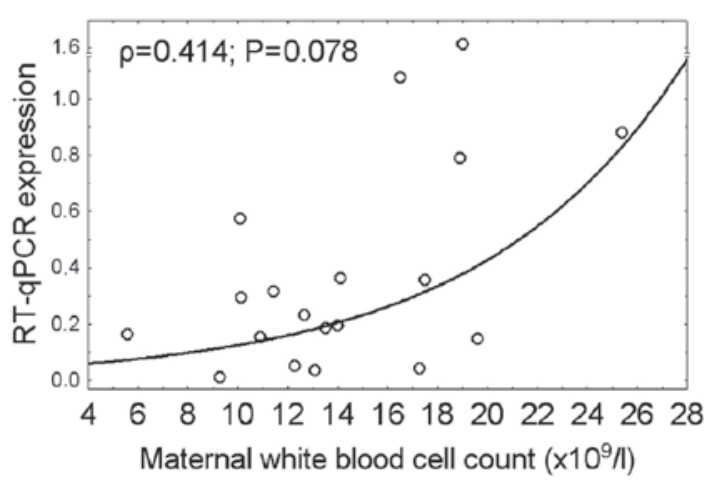

B

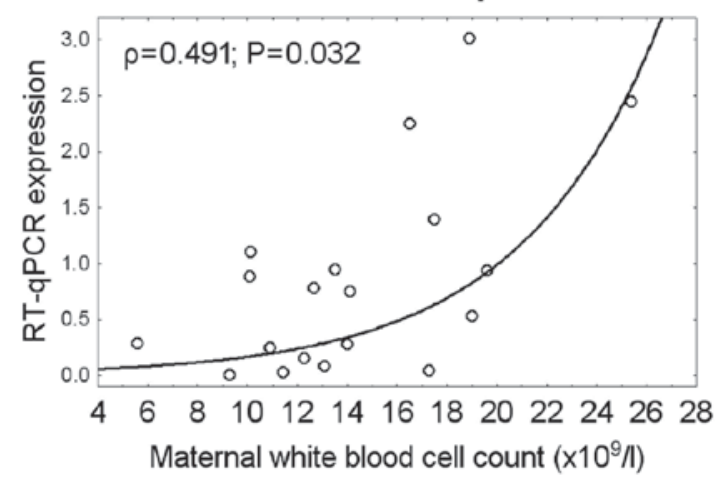

D

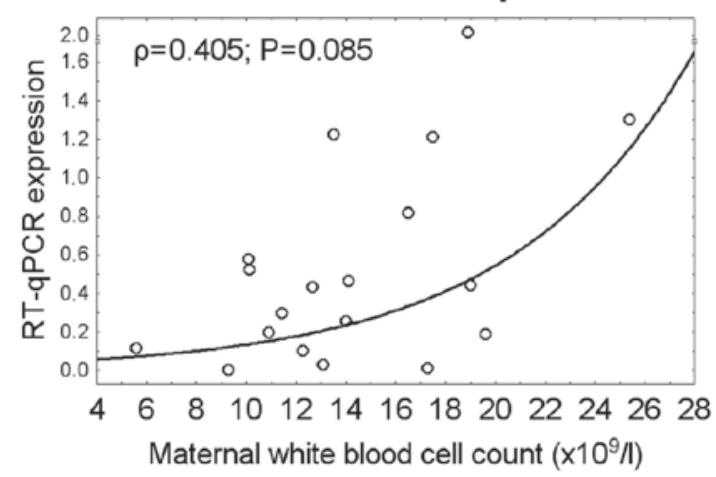

$\mathbf{F}$

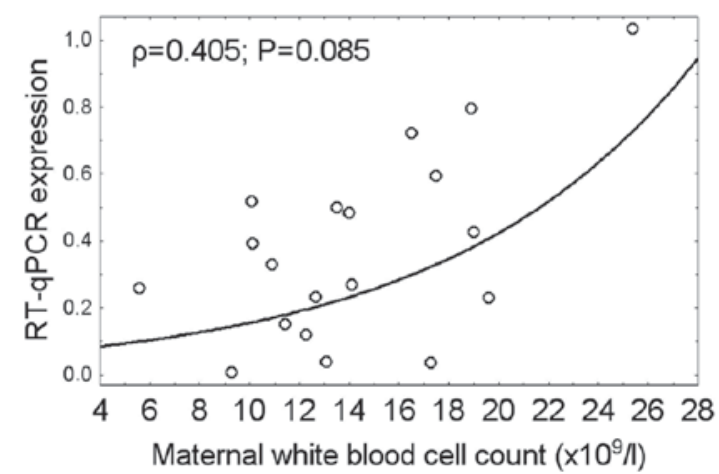

Figure 3. Increase of C19MC microRNA expression in placental tissues with rising maternal WBC count in the group of PTB pregnancies. Correlation between variables including relative microRNA quantification in placental tissues and maternal WBC count at admission (x10 $/ 1)$ in patients with PTB was calculated using the Spearman's rank correlation coefficient (rho). If the correlation coefficient value ranges within $<0.5 ; 1>$, there is a strong positive correlation. If it varies from 0 to 0.5 , there is a weak positive correlation. The significance level was established at $\mathrm{P}<0.05$. $\mathrm{PTB}$ pregnancies showed a strong positive correlation between maternal WBC count at admission and gene expression of (A) miR-515-5p in placental tissues. A positive correlation between the levels of (B) miR512-5p and (C) miR-519e-5p in placental tissues of PTB patients and maternal WBC count at admission was observed. A trend to positive correlation between the levels of (D) miR-516-5p, (E) miR-518b and (F) miR-520h in placental tissues of PTB patients and maternal WBC count at admission was observed. WBC, white blood cell; PTB, preterm birth.

$\rho=-0.132, P=0.624 ;$ miR-525-5p, $\rho=0.069, P=0.799 ;$ miR $-526 a$, $\rho=-0.035, P=0.896$; and $\operatorname{miR}-526 b-5 p, \rho=-0.117, P=0.948$ ).

The association between C19MC microRNA gene expression in placental tissue and maternal WBC count within the groups of PPROM and PTB pregnancies. No association between maternal WBC count at admission and C19MC microRNA gene expression levels in placental tissues was found in the group of PPROM pregnancies.
Nevertheless, in the group of PTB pregnancies a strong positive correlation (miR-515-5p: $\rho=0.508, \mathrm{P}=0.026)$, a positive correlation (miR-512-5p: $\rho=0.491, \mathrm{P}=0.032$; and miR-519e-5p: $\rho=0.457, P=0.048)$, or a trend to positive correlation (miR-516-5p: $\rho=0.405, P=0.085$; miR-518b: $\rho=0.414$, $\mathrm{P}=0.078$; and miR-520h: $\rho=0.405, \mathrm{P}=0.085$ ) between maternal WBC count at admission and some C19MC microRNA gene expression levels in placental tissues was observed (Fig. 3). 


\section{Discussion}

Different C19MC microRNA expression profiles in different cell types within villous tissue and in different areas of placental tissues were documented. The expression of C19MC microRNAs has been observed at least in first-trimester and full-term placental tissues $(73,74)$, human first and third trimester trophoblast cell lines, ACH-3P and AC1-M59 (75), and placenta-derived stromal cells (67). In our initial study, we have observed the presence of all 15 tested C19MC microRNAs (miR-512-5p, miR-515-5p, miR-516-5p, miR-517-5p, miR-518b, miR-518f-5p, miR-519a, miR-519d, miR-519e-5p, miR-520a-5p, miR-520h, miR-524-5p, miR-525-5p, miR-526a and miR-526b-5p) on the fetal side of the placenta (72). In addition, the set of microRNAs (miR-517c, miR-518a, miR-519d, and miR-520h) forming a cluster on chromosome 19 q13 was observed to be expressed in umbilical cord blood CD34+ cells (76).

In addition, our recent study demonstrated that pregnancy-related complications such as gestational hypertension, preeclampsia and fetal growth restriction were associated with downregulation of those C19MC microRNAs that were previously demonstrated to be highly or exclusively expressed in placental tissues (77). The downregulation of 4 of 15 (miR-517-5p, miR-519d, miR-520a-5p and miR-525-5p), 6 of 15 (miR-517-5p, miR-518f-5p, miR-519a, miR-519d, miR-520a-5p and miR-525-5p) and 11 of 15 (miR-515-5p, miR-517-5p, miR-518b, miR-518f-5p, miR-519a, miR-519d, miR-520a-5p, miR-520h, miR-524-5p, miR-525-5p and miR-526a) microRNAs was associated with gestational hypertension, fetal growth restriction, and preeclampsia, respectively. The aim of the current study was to demonstrate if spontaneous PTB and PPROM are also associated with alterations in placental microRNA expression. Overall, the expression profile of studied C19MC microRNAs was different between spontaneous PTB, PPROM, and term in labor pregnancies.

Most of examined C19MC microRNAs were dysregulated in PTB pregnancies. The analysis revealed the upregulation of 9 C19MC microRNAs (miR-515-5p, miR-516-5p, miR-518b, miR-518f-5p, miR-519a, miR-519e-5p, miR-520a-5p, miR-520h and miR-526b-5p) and a trend toward upregulation for other 2 C19MC microRNAs (miR-519d, and miR-526a) in PTB pregnancies. Therefore, it seems that spontaneous PTB has a dissimilar course as term in labor pregnancies.

With regard to PPROM, the analysis indicated that the levels of only 1 out of 15 C19MC microRNAs were significantly decreased in placental tissues samples (miR-525-5p), which indicates that the course of labor in PPROM pregnancies did not differ as much from term in labor pregnancies as the course of labor in PTB pregnancies. Nevertheless, in some ways similar findings to other pregnancy-related complications may be observed in PPROM pregnancies. Downregulation of miR-525-5p was also found in placental tissues derived from patients with gestational hypertension, preeclampsia, and fetal growth restriction (77).

Moreover, clear evidence was brought, that the pathogenesis of spontaneous PTB and PPROM is different. The analysis demonstrated the difference in expression in almost all examined C19MC microRNAs (12 out of 15 C19MC microRNAs reached statistical significance and 1 out of 15 C19MC
microRNAs was on the border of statistical significance). C19MC microRNAs (miR-516b-5p, miR-517-5p, miR-518b, miR-518f-5p, miR-519a, miR-519d, miR-519e-5p, miR-520a-5p, miR-520h, miR-525-5p, miR-526a and miR-526b-5p) were found to be downregulated in placental tissues derived from PPROM pregnancies when compared with gestational age matched PTB pregnancies. A trend toward statistical significance for downregulation of miR-524-5p was observed in PPROM pregnancies.

As the cause of labor still remains elusive, the exact cause of PTB is also unsolved. In fact, the cause of $50 \%$ of PTBs is never determined. Labor is a complex process involving many factors. Four different pathways have been identified that can result in PTB and have considerable evidence: precocious fetal endocrine activation, uterine overdistension (placental abruption), decidual bleeding, and intrauterine inflammation/infection (78). Activation of one or more of these pathways may happen gradually over weeks, even months. From a practical point a number of factors have been identified that are associated with PTB, however, an association does not establish causality. Nevertheless, altered miRNA networks may be a consequence of abnormal physiology leading to PTB. In addition, microRNA alterations can disrupt protein homeostasis and may be at the root of PTB.

While the full repertoire of the biological action of C19MC microRNAs remains to be established, data from various expression studies of C19MC microRNAs imply a role for them in cell proliferation, self-renewal, angiogenesis, and particularly in pro-/anti-cancer activity (79-81). In fact, there is not much research data about the function of C19MC microRNAs in the literature.

Available prediction algorithms usually predict hundreds of potential target genes for a single microRNA, but often generate false-positive candidates (82). Although methods to comprehensively identify miRNAs that regulate individual genes of interest are currently available, pathways involving miRNAs are often complex regulatory networks, whose regulation is difficult to understand. Additionally, it makes the direct interpretation of experimental data complicated. Many genes are targeted for repression by a high number of miRNAs, which seem to regulate those genes cooperatively (83).

The decreased levels of C19MC microRNAs in placental tissues of patients with PPROM may lead to upregulation of relevant proteins involved in the direction of key biological pathways such as premature aging of the fetal membranes where senescence, apoptosis and proteolysis play an important role (84-86). The cause of PPROM is multifactorial and next to intraamniotic infection, reduction in membrane collagen content, stretched membranes, vasculopathy in placentation and decidual haemorrhage are considered to be possible mechanisms underlying PPROM $(33,35)$. We have previously published an extensive list of predicted target genes of all downregulated C19MC microRNAs in patients with gestational hypertension, preeclampsia and fetal growth restriction involved in the regulation of the immune system and the inflammatory response (77).

Among these predicted target genes a lot of those involved in apoptosis were identified (TP53, tumor protein p53; CASP2, Caspase-2, apoptosis-related cysteine peptidase; CASP3, Caspase-3, apoptosis-related cysteine peptidase; CASP10, 
Caspase-10, apoptosis-related cysteine peptidase; BCL2, B-cell CLL/lymphoma 2; BCL10, B-cell CLL/lymphoma 10; TNF, Tumor necrosis factor; TRAF6, TNF receptor associated factor 6; E3, Ubiquitin protein ligase) that have been previously shown to be upregulated in placental tissues derived from patients with preeclampsia and IUGR (77,87-99). Therefore the downregulation of C19MC microRNAs in placental tissues of patients with PPROM may result in increased levels of these proteins, whose levels are exaggerated in pregnancies with other pregnancy-related complications such as preeclampsia and IUGR.

No association between C19MC microRNA gene expression in placental tissues and maternal serum CRP at admission in groups of PPROM and PTB patients was observed.

Likewise, no effect of maternal WBC count on C19MC microRNA gene expression levels of any of the microRNAs in the group of PPROM patients was demonstrated. Both CRP and leukocyte levels were shown to be increased in serum of patients preceding PPROM $(46,100)$. Nevertheless, maternal WBC count and CRP levels are not specific to intrauterine infections and may be influenced by other factors (101). However, in the group of patients with PTB a positive correlation between 3 out of 15 studied C19MC microRNAs (miR-512-5p, miR-515-5p and miR-519e-5p) and maternal WBC count was identified. A trend towards upregulation was observed for other 3 C19MC microRNAs (miR-516-5p, miR-518b and miR-520h) in the group of PTB patients with increased WBC levels.

Nevertheless, in PPROM group all examined C19MC microRNAs displayed decreased expression with advancing gestational age, which suggests a functional involvement of microRNAs in the translational inhibition of multiple mRNA targets. Parallel, Montenegro et al (51) brought similar finding for other 13 microRNAs (miR-199b, miR-373, miR-218, miR-154, miR-338, miR-198, miR-214, miR-370, miR-213, miR-107, miR-199a, miR-222, and miR-330), whose levels were also decreased with advancing gestational age, but this study was performed on chorioamniotic membranes in patients with preterm labor without histologic chorioamnionitis.

In conclusion, this study demonstrated for the first time that PPROM and PTB were associated with altered C19MC microRNA expression profile. The expression profile of placental specific microRNAs was the most distinct between PTB group and women at term in labor, and between gestational age-matched PPROM and PTB groups.

\section{Acknowledgements}

The study was supported by the Charles University research programmes (nos. PRVOUK P32 and 260275/SVV/2016).

\section{References}

1. American College of Obstetricians and Gynecologists; Committee on Practice Bulletins-Obstetrics: ACOG practice bulletin no. 127: Management of preterm labor. Obstet Gynecol 119: 1308-1317, 2012.

2. Goldenberg RL, Culhane JF, Iams JD and Romero R: Epidemiology and causes of preterm birth. Lancet 371: 75-84, 2008.

3. Martin JA, Hamilton BE, Ventura SJ, Menacker F, Park MM and Sutton PD: Births: Final data for 2001. Natl Vital Stat Rep 51: $1-102,2002$.
4. McCormic MC: The contribution of low birth weight to infant mortality and childhood morbidity. N Engl J Med 312: 82-90, 1985.

5. Saigal S and Doyle LW: An overview of mortality and sequelae of preterm birth from infancy to adulthood. Lancet 371: 261-269, 2008.

6. Mathews TJ, Menacker F and MacDorman MF; Centrs for Disease Control and Prevention, National Center for Health Statistics: Infant mortality statistics from the 2002 period: Linked birth/infant death data set. Natl Vital Stat Rep 53: 1-29, 2004.

7. Hack M and Fanaroff AA: Outcomes of children of extremely low birthweight and gestational age in the 1990s. Semin Neonatol 5: 89-106, 1999.

8. Moutquin JM, Milot Roy V and Irion O: Preterm prevention: Effectivenss of current strategies. J Soc Obstet Gynaecol Can 18: 571-588, 1996.

9. Romero R, Espinoza J, Kusanovic JP, Gotsch F, Hassan S, Erez O, Chaiworapongsa $\mathrm{T}$ and Mazor M: The preterm parturition syndrome. BJOG 113 (Suppl 3): S17-S42, 2006.

10. Rosen T, Kuczynski E, O'Neill LM, Funai EF and Lockwood CJ: Plasma levels of trombin-antithrombin complexes predict preterm premature rupture of fetal membranes. J Matern Fetal Med 10: 297-300, 2001

11. Tian CF, Lv FH, Wang M and Gu XS: Serum $\beta$-human chorionic gonadotropin and interleukin-1 as diagnostic biomarkers for the premature rupture of membranes and chorioamnionitis. Biomed Rep 2: 905-909, 2014.

12. Anderson P and Doyle LW; Victorian Infant Collaborative Study Group: Neurobehavioral outcomes of school-age children born extremely low birth weight or very preterm in 1990s. JAMA 289: 3264-3272, 2003.

13. Bhutta AT, Cleves MA, Casey PH, Cradock MM and Anand KJ: Cognitive and behavioral outcomes of school-aged children who were born preterm: A meta-analysis. JAMA 288: 728-737, 2002.

14. Marlow N, Wolker D, Bracewell MA and Samara M; EPICure Study Group: Neurologic and developmental disability at six years of age after extremely preterm birth. N Engl J Med 352: 9-19, 2005.

15. Hack M, Taylor HG, Drotar D, Schluchter M, Cartar L, Andreias L, Wilson-Costello D and Klein N: Chronic conditions, functional limitations, and special health care needs of school-aged children born with extremely low-birth-weight in the 1990s. JAMA 294: 318-325, 2005.

16. Slattery MM and Morrison JJ: Preterm delivery. Lancet 360: 1489-1497, 2002

17. El-Bastawissi AY, Williams MA, Riley DE, Hitti J and Krieger JN: Amniotic fluid interleukin-6 and preterm delivery: A review. Obstet Gynecol 95: 1056-1064, 2000.

18. Petrou S, Mehta Z, Hockley C, Cook-Mozaffari P, Henderson J and Goldacre M: The impact of preterm birth on hospital inpatient admissions and costs during the first 5 years of life. Pediatrics 112: 1290-1297, 2003.

19. Petrou S: The economic consequences of preterm birth during the first 10 years of life. BJOG 112 (Suppl 1): S10-S15, 2005.

20. Guinn DA, Goldenberg RL, Hauth JC, Andrews WW, Thom E and Romero R: Risk factors for the development of preterm premature rupture of the membranes after arrest of preterm labor. Am J Obstet Gynecol 173: 1310-1315, 1995.

21. Goldenberg RL, Hauth JC and Andrews WW: Intrauterine infection and preterm delivery. N Engl J Med 342: 1500-1507, 2000.

22. Challis JR, Lockwood CJ, Myatt L, Norman JE, Strauss JF III and Petraglia F: Inflammation and pregnancy. Reprod Sci 16: 206-215, 2009.

23. Keelan JA: Pharmacological inhibition of inflammatory pathways for the prevention of preterm birth. J Reprod Immunol 88: 176-184, 2011.

24. Williams MA, Mittendorf R, Stubblefield PG, Lieberman E, Schoenbaum SC and Monson RR: Cigarettes, coffee, and preterm premature rupture of the membranes. Am J Epidemiol 135: 895-903. 1992.

25. Ekwo EE, Gosselink CA, Woolson R and Moawad A: Risks for premature rupture of amniotic membranes. Int J Epidemiol 22: 495-503, 1993.

26. Hadley CB, Main DM and Gabbe SG: Risk factors for preterm premature rupture of the fetal membranes. Am J Perinatol 7: 374-379, 1990.

27. Naeye RL and Peters EC: Causes and consequences of premature rupture of fetal membranes. Lancet 1: 192-194, 1980.

28. Menon R, Taylor RN and Fortunato SJ: Chorioamnionitis-a complex pathophysiologic syndrome. Placenta 31: 113-120, 2010. 
29. Tita AT and Andrews WW: Diagnosis and management of clinical chorioamnionitis. Clin Perinatol 37: 339-354, 2010.

30. Musilova I, Kutová R, Pliskova L, Stepan M, Menon R, Jacobsson B and Kacerovsky M: Intraamniotic inflammation in women with preterm prelabor rupture of membranes. PLoS One 10: e0133929, 2015.

31. Simhan HN and Canavan TP: Preterm premature rupture of membranes: Diagnosis, evaluation and management strategies. BJOG 112 (Suppl 1): S32-S37, 2005.

32. Gibbs RS and Blanco JD: Premature rupture of the membranes. Obstet Gynecol 60: 671-679, 1982.

33. Parry S and Strauss JF III: Premature rupture of the fetal membranes. N Engl J Med 338: 663-670, 1998

34. Garite TJ: Management of premature rupture of membranes. Clin Perinatol 28: 837-847, 2001.

35. Mercer BM: Preterm premature rupture of membranes. Obstet Gynecol 101: 178-193, 2003.

36. Shubert PJ, Diss E and Iams JD: Etiology of preterm premature rupture of membranes. Obstet Gynecol Clin North Am 19: 251-263, 1992.

37. Lee $\mathrm{T}$ and Silver H: Etiology and epidemiology of preterm premature rupture of the membranes. Clin Perinatol 28: 721-734, 2001.

38. Ernest JM, Meis PJ, Moore ML and Swain M: Vaginal pH: A marker of preterm premature rupture of the membranes. Obstet Gynecol 74: 734-738, 1989.

39. Phocas I, Sarandakou A, Kontoravdis A, Chryssicopoulos A and Zourlas PA: Vaginal fluid prolactin: A reliable marker for the diagnosis of prematurely ruptured membranes. Comparison with vaginal fluid alpha-fetoprotein and placental lactogen. Eur J Obstet Gynecol Reprod Biol 31: 133-141, 1989.

40. Yamada $\mathrm{H}$ and Fujimoto S: Rapid diagnosis of premature rupture of membranes using a new kit employing anti-AFP monoclonal antibody. Arch Gynecol Obstet 256: 57-61, 1995.

41. Kishida T, Yamada H, Negishi H, Sagawa T, Makinoda S and Fujimoto S: Diagnosis of preterm premature rupture of the membranes using a newly developed AFP monoclonal antibody test kit. Eur J Obstet Gynecol Reprod Biol 58: 67-72, 1995.

42. Rutanen EM, Kärkkäinen TH, Lehtovirta J, Uotila JT, Hinkula MK and Hartikainen AL: Evaluation of a rapid strip test for insulin-like growth factor binding protein-1 in the diagnosis of ruptured fetal membranes. Clin Chim Acta 253: 91-101. 1996

43. Anai T, Tanaka Y, Hirota Y and Miyakawa I: Vaginal fluid hCG levels for detecting premature rupture of membranes. Obstet Gynecol 89: 261-264, 1997.

44. Revah A, Hannah ME and Sue-A-Quan AK: Fetal fibronectin as a predictor of preterm birth: An overview. Am J Perinatol 15: 613-621, 1998

45. Odibo AO, Berghella V, Reddy U, Tolosa JE and Wapner RJ: Does transvaginal ultrasound of the cervix predict preterm premature rupture of membranes in a high-risk population? Ultrasound Obstet Gynecol 18: 223-227, 2001

46. Moghaddam Banaem L, Mohamadi B, Asghari Jaafarabadi M and Aliyan Moghadam N: Maternal serum C-reactive protein in early pregnancy and occurrence of preterm premature rupture of membranes and preterm birth. J Obstet Gynaecol Res 38 : 780-786, 2012

47. She BQ, Chen SC, Lee FK, Cheong ML and Tsai MS: Low maternal serum levels of pregnancy associated plasma protein-A during the first trimester are associated with subsequent preterm delivery with preterm premature rupture of membranes. Taiwan J Obstet Gynecol 46: 242-247, 2007.

48. Vigeh M, Yokoyama K, Shinohara A, Afshinrokh M and Yunesian M: Early pregnancy blood lead levels and the risk of premature rupture of the membranes. Reprod Toxicol 30: 477-480, 2010.

49. Rayman MP, Wijnen H, Vader H, Kooistra L and Pop V: Maternal selenium status during early gestation and risk of preterm birth CMAJ 183: 549-555, 2011.

50. Ekin A, Gezer C, Kulhan G, Avci ME and Taner CE: Can platelet count and mean platelet volume during the first trimester of pregnancy predict preterm premature rupture of membranes? J Obstet Gynaecol Res 41: 23-28, 2015.

51. Montenegro D, Romero R, Pineles BL, Tarca AL, Kim YM, Draghici S, Kusanovic JP, Kim JS, Erez O, Mazaki-Tovi S, et al: Differential expression of microRNAs with progression of gestation and inflammation in the human chorioamniotic membranes. Am J Obstet Gynecol 197: 289.e1-e6, 2007.
52. Montenegro D, Romero R, Kim SS, Tarca AL, Draghici S, Kusanovic JP, Kim JS, Lee DC, Erez O, Gotsch F, et al: Expression patterns of microRNAs in the chorioamniotic membranes: A role for microRNAs in human pregnancy and parturition. J Pathol 217: 113-121, 2009.

53. Mayor-Lynn K, Toloubeydokhti T, Cruz AC and Chegini N: Expression profile of microRNAs and mRNAs in human placentas from pregnancies complicated by preeclampsia and preterm labor. Reprod Sci 18: 46-56, 2011.

54. Elovitz MA, Brown AG, Anton L, Gilstrop M, Heiser L and Bastek J: Distinct cervical microRNA profiles are present in women destined to have a preterm birth. Am J Obstet Gynecol 210: 221.e1-e11, 2014.

55. Sanders AP, Burris HH, Just AC, Motta V, Svensson K, Mercado-Garcia A, Pantic I, Schwartz J, Tellez-Rojo MM, Wright RO and Baccarelli AA: microRNA expression in the cervix during pregnancy is associated with length of gestation. Epigenetics 10: 221-228, 2015.

56. Elovitz MA, Anton L, Bastek J and Brown AG: Can microRNA profiling in maternal blood identify women at risk for preterm birth? Am J Obstet Gynecol 212: 782.e1-e5, 2015.

57. Pineles BL, Romero R, Montenegro D, Tarca AL, Han YM, Kim YM, Draghici S, Espinoza J, Kusanovic JP, Mittal P, et al: Distinct subsets of microRNAs are expressed differentially in the human placentas of patients with preeclampsia. Am J Obstet Gynecol 196: 261.e1-e6, 2007.

58. Hu Y, Li P, Hao S, Liu L, Zhao J and Hou Y: Differential expression of microRNAs in the placentae of Chinese patients with severe pre-eclampsia. Clin Chem Lab Med 47: 923-929, 2009.

59. Zhu XM, Han T, Sargent IL, Yin GW and Yao YQ: Differential expression profile of microRNAs in human placentas from preeclamptic pregnancies vs normal pregnancies. Am J Obstet Gynecol 200: 661.e1-e7, 2009.

60. Maccani MA, Padbury JF and Marsit CJ: miR-16 and miR-21 expression in the placenta is associated with fetal growth. PLoS One 6: e21210, 2011.

61. Enquobahrie DA, Abetew DF, Sorensen TK, Willoughby D, Chidambaram K and Williams MA: Placental microRNA expression in pregnancies complicated by preeclampsia. Am J Obstet Gynecol 204: 178.e12-e21, 2011.

62. Higashijima A, Miura K, Mishima H, Kinoshita A, Jo O, Abe S, Hasegawa Y, Miura S, Yamasaki K, Yoshida A, et al: Characterization of placenta-specific microRNAs in fetal growth restriction pregnancy. Prenat Diagn 33: 214-222, 2013.

63. Bortolin-Cavaillé ML, Dance M, Weber M and Cavaillé J: C19MC microRNAs are processed from introns of large Pol-II, non-protein-coding transcripts. Nucleic Acids Res 37: 3464-3473, 2009.

64. Noguer-Dance M, Abu-Amero S, Al-Khtib M, Lefèvre A, Coullin P, Moore GE and Cavaillé J: The primate-specific microRNA gene cluster (C19MC) is imprinted in the placenta. Hum Mol Genet 19: 3566-3582, 2010.

65. Vaira V, Elli F, Forno I, Guarnieri V, Verdelli C, Ferrero S, Scillitani A, Vicentini L, Cetani F, Mantovani G, et al: The microRNA cluster $\mathrm{C} 19 \mathrm{MC}$ is deregulated in parathyroid tumours. J Mol Endocrinol 49: 115-124, 2012

66. Rippe V, Dittberner L, Lorenz VN, Drieschner N, Nimzyk R, Sendt W, Junker K, Belge G and Bullerdiek J: The two stem cell microRNA gene clusters C19MC and miR-371-3 are activated by specific chromosomal rearrangements in a subgroup of thyroid adenomas. PLoS One 5: e9485, 2015.

67. Flor I and Bullerdiek J: The dark side of a success story: microRNAs of the C19MC cluster in human tumours. J Pathol 227: 270-274, 2012.

68. Augello C, Vaira V, Caruso L, Destro A, Maggioni M, Park YN, Montorsi M, Santambrogio R, Roncalli M and Bosari S: MicroRNA profiling of hepatocarcinogenesis identifies C19MC cluster as a novel prognostic biomarker in hepatocellular carcinoma. Liver Int 32: 772-782, 2012.

69. Liang Y, Ridzon D, Wong L and Chen C: Characterization of microRNA expression profiles in normal human tissue. BMC Genomics 8: 166, 2007.

70. Livak KJ and Schmittgen TD: Analysis of relative gene expression data using real-time quantitative PCR and the 2(-Delta Delta C(T)) Method. Methods 25: 402-408, 2001.

71. Vandesompele J, De Preter K, Pattyn F, Poppe B, Van Roy N, De Paepe A and Speleman F: Accurate normalization of real-time quantitative RT-PCR data by geomeztic averaging of multiple internal control genes. Genom Biol 3: RESEARCH0034, 2002 
72. Kotlabova K, Doucha J and Hromadnikova I: Placental-specific microRNA in maternal circulation- identification of appropriate pregnancy-associated microRNAs with diagnostic potential. J Reprod Immunol 89: 185-191, 2011.

73. Luo SS, Ishibashi O, Ishikawa G, Ishikawa $T$, Katayama $A$ Mishima T, Takizawa T, Shigihara T, Goto T, Izumi A, et al: Human villous trophoblasts express and secrete placenta-specific microRNAs into maternal circulation via exosomes. Biol Reprod 81: 717-729, 2009.

74. Wang D, Song $\mathrm{W}$ and Na Q: The emerging roles of placenta-specific microRNAs in regulating trophoblast proliferation during the first trimester. Aust N Z J Obstet Gynaecol 52: 565-570, 2012.

75. Morales-Prieto DM, Chaiwangyen W, Ospina-Prieto S, Schneider U, Herrmann J, Gruhn B and Markert UR: MicroRNA expression profiles of trophoblastic cells. Placenta 33: 725-734, 2012.

76. Merkerova M, Vasikova A, Belickova M and Bruchova $\mathrm{H}$ MicroRNA expression profiles in umbilical cord blood cell lineages. Stem Cells Dev 19: 17-26, 2010.

77. Hromadnikova I, Kotlabova K, Ondrackova M, Pirkova P, Kestlerova A, Novotna V, Hympanova L and Krofta L: Expression profile of C19MC microRNAs in placental tissue in pregnancy-related complications. DNA Cell Biol 34: 437-457, 2015.

78. Simhan HN and Caritis SN: Prevention of preterm delivery. N Engl J Med 357: 477-487, 2007.

79. Li M, Lee KF, Lu Y, Clarke I, Shih D, Eberhart C, Collins VP, Van Meter T, Picard D, Zhou L, et al: Frequent amplification of a chr19q13.41 microRNA polycistron in aggressive primitive neuroectodermal brain tumors. Cancer Cell 16: 533-546, 2009.

80. Ouyang Y, Mouillet JF, Coyne CB and Sadovsky Y: Review: Placenta-specific microRNAs in exosomes - good things come in nano-packages. Placenta 35 (Suppl): S69-S73, 2014.

81. Keung MH, Chan LS, Kwok HH, Wong RN and Yue PY: Role of microRNA-520h in 20(R)-ginsenoside-Rg3-mediated angiosuppression. J Ginseng Res 40: 151-159, 2016.

82. Portilho DM, Alves MR, Kratassiouk G, Roche S, Magdinier F, de Santana EC, Polesskaya A, Harel-Bellan A, Mouly V, Savino W, et al: miRNA expression in control and FSHD fetal human muscle biopsies. PLoS One 10: e0116853, 2015.

83. Schmitz U, Wolkenhauer O and Vera J (eds): MicroRNA Cancer Regulation: Advanced Concepts, Bioinformatics and Systems Biology Tools. Springer, Berlin, 2013.

84. Menon R, Boldogh I, Hawkins HK, Woodson M, Polettini J, Syed TA, Fortunato SJ, Saade GR, Papaconstantinou J and Taylor RN: Histological evidence of oxidative stress and premature senescence in preterm premature rupture of the human fetal membranes recapitulated in vitro. Am J Pathol 184: 1740-1751, 2014

85. Menon R, Polettini J, Syed TA, Saade GR and Boldogh I: Expression of 8-oxoguanine glycosylase in human fetal membranes. Am J Reprod Immunol 72: 75-84, 2014.

86. Menon R, Yu J, Basanta-Henry P, Brou L, Berga SL, Fortunato SJ and Taylor RN: Short fetal leukocyte telomere length and preterm prelabor rupture of the membranes. PLoS One 7: e31136, 2013.

87. FornariF,MilazzoM,ChiecoP,NegriniM,MarascoE,CapranicoG, Mantovani V, Marinello J, Sabbioni S, Callegari E, et al: In hepatocellular carcinoma miR-519d is up-regulated by p53 and DNA hypomethylation and targets CDKN1A/p21, PTEN, AKT3 and TIMP2. J Pathol 227: 275-285, 2012.
88. Huang Y, Chuang A, Hao H, Talbot C, Sen T, Trink B, Sidransky D and Ratovitski E. Phospho- $\Delta$ Np63 $\alpha$ is a key regulator of the cisplatin-induced microRNAome in cancer cells. Cell Death Differ 18: 1220-1230, 2011.

89. Martinelli R, Nardelli C, Pilone V, Buonomo T, Liguori R, Castanò I, Buono P, Masone S, Persico G, Forestieri P, et al: miR-519d overexpression is associated with human obesity. Obesity (Silver Spring) 18: 2170-2176, 2010

90. Ye W, Lv Q, Wong CK, Hu S, Fu C, Hua Z, Cai G, Li G, Yang BB and Zhang Y: The effect of central loops in miRNA:MRE duplexes on the efficiency of miRNA-mediated gene regulation. PLoS One 3: e1719, 2008.

91. Yoshitomi T, Kawakami K, Enokida H, Chiyomaru T, Kagara I, Tatarano S, Yoshino H, Arimura H, Nishiyama K, Seki N and Nakagawa M: Restoration of miR-517a expression induces cell apoptosis in bladder cancer cell lines. Oncol Rep 25: 1661-1668, 2011.

92. Sharp AN, Heazell AE, Baczyk D, Dunk CE, Lacey HA, Jones CJ, Perkins JE, Kingdom JC, Baker PN and Crocker IP: Preeclampsia is associated with alterations in the p53-pathway in villous trophoblast. PLoS One 9: e87621, 2014

93. Han JY, Kim YS, Cho GJ, Roh GS, Kim HJ, Choi WJ, Paik WY, Rho GJ, Kang SS and Choi WS: Altered gene expression of caspase-10, death receptor-3 and IGFBP-3 in preeclamptic placentas. Mol Cells 22: 168-174, 2006.

94. Cali U, Cavkaytar S, Sirvan L and Danisman N: Placental apoptosis in preeclampsia, intrauterine growth retardation and HELLP syndrome: An immunohistochemical study with caspase-3 and bcl-2. Clin Exp Obstet Gynecol 40: 45-48, 2013.

95. Ishioka S, Ezaka Y, Umemura K, Hayashi T, Endo T and Saito T: Proteomic analysis of mechanisms of hypoxia-induced apoptosis in trophoblastic cells. Int J Med Sci 4: 36-44, 2006.

96. Whitehead CL, Walker SP, Lappas M and Tong S: Circulating RNA coding genes regulating apoptosis in maternal blood in severe early onset fetal growth restriction and pre-eclampsia. J Perinatol 33: 600-604, 2013

97. Lamarca B: Endothelial dysfunction. An important mediator in the pathophysiology of hypertension during pre-eclampsia. Minerva Ginecol 64: 309-320, 2012.

98. Tosun M, Celik H, Avci B, Yavuz E, Alper T and Malatyalioğlu E: Maternal and umbilical serum levels of interleukin-6, interleukin- 8 and tumor necrosis factor-alpha in normal pregnancies and in pregnancies complicated by preeclampsia. J Matern Fetal Neonatal Med 23: 880-886, 2010

99. Zhou P, Luo X, Qi HB, Zong WJ, Zhang H, Liu DD and Li QS The expression of pentraxin 3 and tumor necrosis factor-alpha is increased in preeclamptic placental tissue and maternal serum. Inflamm Res 61: 1005-1012, 2012.

100. Tzur T, Weintraub AY, Sergienko R and Sheiner E: Can leukocyte count during the first trimester of pregnancy predict later gestational complications? Arch Gynecol Obstet 287: 421-427, 2013.

101. Le J (ed): Obstetrics and Gynecology. 7th edition. Beijing People's Medical Publishing House, Beijing, pp137-138, 2008. 